\title{
Phosphatidylinositol 3-Kinase and Akt Nonautonomously Promote Perineurial Glial Growth in Drosophila Peripheral Nerves
}

\author{
William Lavery, Veronica Hall, James C. Yager, Alex Rottgers, Michelle C. Wells, and Michael Stern \\ Department of Biochemistry and Cell Biology, Rice University, Houston, Texas 77251
}

\begin{abstract}
Drosophila peripheral nerves, structured similarly to their mammalian counterparts, comprise a layer of motor and sensory axons wrapped by an inner peripheral glia (analogous to the mammalian Schwann cell) and an outer perineurial glia (analogous to the mammalian perineurium). Growth and proliferation within mammalian peripheral nerves are increased by Ras pathway activation: loss-of-function mutations in $\mathrm{Nfl}$, which encodes the Ras inhibitor neurofibromin, cause the human genetic disorder neurofibromatosis, which is characterized by formation of neurofibromas (tumors of peripheral nerves). However, the signaling pathways that control nerve growth downstream of Ras remain incompletely characterized. Here we show that expression specifically within the Drosophila peripheral glia of the constitutively active $\operatorname{Ras}^{V 12}$ increases perineurial glial thickness. Using chromosomal loss-of-function mutations and transgenes encoding dominant-negative and constitutively active proteins, we show that this nonautonomous effect of $\operatorname{Ras}^{V 12}$ is mediated by the Ras effector phosphatidylinositol 3-kinase (PI3K) and its downstream kinase Akt. We also show that the nonautonomous, growthpromoting effects of activated PI3K are suppressed by coexpression within the peripheral glia of $\mathrm{FOXO}^{+}$(forkhead box 0 ) a transcription factor inhibited by Akt-dependent phosphorylation. We suggest that Ras-PI3K-Akt activity in the peripheral glia promotes growth of the perineurial glia by inhibiting FOXO. In mammalian peripheral nerves, the Schwann cell releases several growth factors that affect the proliferative properties of neighbors. Some of these factors are oversecreted in Nf1 mutants. Our results raise the possibility that neurofibroma formation in individuals with neurofibromatosis might result in part from a Ras-PI3K-Akt-dependent inhibition of FOXO within Schwann cells.
\end{abstract}

Key words: neurofibromatosis; Ras; FOXO; cell growth; cell nonautonomy; Schwann cell

\section{Introduction}

Peripheral nerves in both Drosophila and mammals contain an inner layer of motor and sensory axons surrounded by an inner peripheral glial layer (termed the Schwann cell in mammals) and an outer, mesodermally derived perineurial glia (termed the perineurium in mammals). Proper growth, development, and function of peripheral nerves require intercellular signaling among the cell types present. For example, formation of the perineurial sheath requires Desert Hedgehog secretion from Schwann cells (Parmantier et al., 1999). In addition, neurons and glia interact reciprocally to regulate function, at least in part through the release of, and response to, small molecule neurotransmitters (Colomar and Robitaille, 2004; Yuan and Ganetzky, 1999).

Individuals with the autosomal-dominant genetic disorder of

Received Aug. 4, 2006; revised Nov. 2, 2006; accepted Dec. 4, 2006.

This work was supported by Department of Defense Neurofibromatosis Research Program Grant W81XWH-041-0272 (M.S.). We are grateful to Angela Lynn, Vanathi Sundaresan, and Gia Fazio for technical assistance and Ke Ito, Vanessa Auld, Marc Tatar, Hideyuki Okano, Sally Leevers, Ernst Hafen, Exelixis Corporation, and the Bloomington Drosophila Stock Center (University of Indiana, Bloomington, IN) for fly stocks.

Correspondence should be addressed to Michael Stern, Department of Biochemistry and Cell Biology MS-140, Rice University, P.0. Box 1892, Houston, TX 77251-1892. E-mail: stern@rice.edu.

V. Hall's present address: Laboratory of Experimental Immunology, Center for Cancer Research, National Cancer Institute, Frederick Building 560/31-93, Frederick, MD 21702.

DOI:10.1523/JNEUROSCI.3370-06.2007

Copyright $\odot 2007$ Society for Neuroscience $\quad$ 0270-6474/07/270279-10\$15.00/0 neurofibromatosis, which is caused by mutations in Nf1 (for review, see Cichowski and Jacks, 2001), form peripheral nerve tumors called neurofibromas at high frequency. Neurofibromas are thought to arise in individuals heterozygous for Nf1 after spontaneous loss of the $\mathrm{Nf1}^{+}$allele within Schwann cells (Kluwe et al., 1999; Serra et al., 2000). NF1 encodes a Ras GTPase activator and thus negatively regulates Ras. Although at least some of the growth deficits of $\mathrm{Nf1}^{-}$cells result from Ras hyperactivation, the Ras effector pathways mediating the various growth defects have not been fully characterized. It was reported recently that phosphatidylinositol 3-kinase (PI3K), Akt, and the Akt-dependent kinase Tor (target of rapamycin) are hyperactivated in Nf1deficient mouse or human cells and that this activation was required for proliferation of tumor cells in culture (Dasgupta et al., 2005; Johannessen et al., 2005). These results are consistent with the well established role for the PI3K-Tor pathway in autonomous growth control (Hay and Sonenberg, 2004). However, there is much evidence that neurofibroma formation requires Schwann cell nonautonomous pathways (Sherman et al., 2000; Yang et al., 2003). For example, neurofibromas are heterogeneous at the cellular level and contain cell types that are not clonally related (i.e., Schwann cells and fibroblasts). This observation raises the possibility that neurofibroma formation requires the $\mathrm{Nfl}^{-}$-dependent oversecretion of growth factors that 
increase the proliferation of heterozygous neighbors (Yang et al., 2003). The identity of the pathway(s) regulating nonautonomous growth has not been elucidated.

Here we use the Drosophila peripheral nerve to identify molecules acting within the peripheral glia that regulate growth nonautonomously. We find that expression of constitutively active $R a s^{V 12}$ specifically within the peripheral glia increases perineurial glial thickness. We also show that this nonautonomous, growthactivating effect is mediated by PI3K and Akt: PI3K and Akt activity within the peripheral glia are both necessary and sufficient to promote nonautonomous growth. Finally, we report that peripheral glial overexpression of FOXO (forkhead box $\mathrm{O}$ ), which encodes a transcription factor inhibited by Akt-dependent phosphorylation and which antagonizes PI3K-Akt-dependent gene expression (Puig et al., 2003), suppresses the growthpromoting effects of activated PI3K. We conclude that the effect of Ras activity within the peripheral glia on perineurial glial growth is mediated by PI3K and Akt and suggest that this pathway promotes nonautonomous growth by inhibiting FOXO.

\section{Materials and Methods}

Drosophila stocks, mutations, and crosses. Gliotactin ( gli)-Gal4 and MZ709 express Gal4 in peripheral glia (Ito et al., 1995; Auld et al., 1995; Leiserson et al., 2000; Sepp and Auld, 1999) and were provided by Vanessa Auld (University of British Columbia, Vancouver, British Columbia, Canada) and Kei Ito (National Institute for Basic Biology, Okazaki, Japan), respectively; upstream activating sequence (UAS)-PI3K-CAAX and $U A S-P I 3 K^{D 954 A}$ express a constitutively active and dominantnegative PI3K, respectively, under the transcriptional control of Gal4 (Leevers et al., 1996) and were provided by Sally Leevers (Cancer Research Institute, London, UK); flies bearing UAS-Ras ${ }^{V 12}$ (strong) on chromosome III, UAS-Ras ${ }^{+}$(Lee et al., 1996; Karim and Rubin, 1998), UAS-Raf ${ }^{F 179}$ (Brand and Perrimon, 1994), UAS-green fluorescent protein (GFP) nuclear localization signal (nls) (Shiga et al., 1996), and $A k t^{4226}$ (Perrimon et al., 1996) were provided by the Bloomington Drosophila Stock Center (University of Indiana, Bloomington, IN). Two independent $U A S-A k t$ transgenes (A. Park, personal communication to FlyBase) were provided by the Bloomington Drosophila Stock Center via Exelixis (South San Francisco, CA). UAS-Ras ${ }^{V 12}$ (weak) on chromosome II (Karim and Rubin, 1998) was provided by Andreas Bergmann (M. D. Anderson Cancer Research Center, Houston, TX). UAS-Ral ${ }^{\mathrm{V} 20}$ (Sawamoto et al., 1999) was provided by Hideyuki Okano (Tokyo, Japan). Two independent $U A S-F O X O^{+}$transgenes (Junger et al., 2003; Hwangbo et al., 2004) were provided by Marc Tatar (Providence, RI). Flies bearing two loss-of-function alleles of PI3K: $P I 3 K^{2 H 1}$ and $P I 3 K^{A}$ (Halfar et al., 2001), provided by Ernst Hafen (Zurich, Switzerland).

Standard Drosophila genetics techniques were used to establish the fly stocks and perform the crosses used in the experiments described. Because the PI $3 \mathrm{~K}$ and $A k t$ loss-of-function alleles used confer either lethality or greatly reduced viability when homozygous, these alleles were maintained with balancers carrying the tubby $T b$ dominant marker, which can be scored in larvae. Third-instar larvae carrying the Akt or PI3K mutant alleles on both chromosomes, to be analyzed with electron microscopy, were recognized by their non-tubby appearance. For all experiments using either Gal4 or UAS transgenes, the appropriate larvae were obtained after a cross of the Gal4-containing fly line to the UAScontaining fly line. Because UAS-PI3K-CAAX is located on the X chromosome, only female larvae heterozygous for these transgenes were analyzed. In all cases, larvae bearing the Gal4 driver alone or the UASdriven transgene alone were generated in parallel to the experimental larvae and used as controls.

Transmission electron microscopy. Larvae were grown to the wandering third-instar stage in uncrowded half-pint bottles at room temperature $\left(22-23^{\circ} \mathrm{C}\right)$. Larvae were collected only during the first and second days after the initial third-instar larvae appeared. The dissections, fixations, and stainings were performed as described previously (Yager et al., 2001). Perineurial glial thickness was measured from the edge of the nerve to the axon-containing lumen and averaged from eight measurements made 12:00, 3:00, 6:00, and 9:00 and four positions in between. Measurements were not taken at positions in nerves in which a perineurial glial nucleus was encountered.

Fluorescence microscopy. Larvae were grown to the wandering thirdinstar stage as described above. These larvae were dissected with the protocol used for electron microscopy, except PBS was used for dissections. Dissected larvae were fixed in PBS containing 5\% formaldehyde and $0.1 \%$ Triton X-100 for 15 min. Ventral ganglia and nerves were removed and placed in Vectashield (H-1000; Vector Laboratories, Burlingame, CA) containing a 1:1000 dilution of Hoechst stain (H-3570; Invitrogen, Carlsbad, CA). Nuclei were visualized with $4^{\prime}, 6^{\prime}$-diamidino2-phenylindole and GFP filters on an Axioplan 2 epifluorescence microscope (Zeiss, Oberkochen, Germany) using MetaMorph software for micrograph acquisition (Molecular Devices, Palo Alto, CA).

\section{Results \\ gli-Gal4 and MZ709: two Gal4 drivers that express in the peripheral glia but not the perineurial glia.}

Drosophila peripheral nerves contain a layer of $\sim 80$ motor and sensory axons, wrapped by an inner peripheral glia, which forms the blood-nerve barrier (Auld et al., 1995) and an outer, mesodermally derived perineurial glia (Edwards et al., 1993). A transmission electron micrograph (TEM) of a peripheral nerve cross section is shown in Figure $1 A$. Each peripheral nerve contains approximately eight peripheral glial nuclei (Sepp et al., 2000). In addition, each $\mathrm{mm}$ of peripheral nerve contains $\sim 20$ perineurial glial nuclei (W. Lavery and M. Stern, unpublished observations).

To evaluate the role of Ras signaling in nonautonomous growth control within peripheral nerves, we used the Gal4/UAS system (Brand and Perrimon, 1993) to express wild-type and mutant transgenes specifically within the peripheral glia. Two Gal4 drivers, gli-Gal4 and MZ709, were reported to express in the peripheral glia but not the neurons of peripheral nerves (Ito et al., 1995; Sepp and Auld, 1999; Leiserson et al., 2000; Sepp et al., 2000). The gli-Gal4 driver is a particularly well characterized marker for peripheral glia. gli-Gal4 was generated via gene conversion from a gli-lacZ enhancer trap line (Auld et al., 1995; Sepp and Auld, 1999), which was reported to express specifically in peripheral glia, exit glia, and some midline glia. The gli-Gal4 driver was used to study peripheral glial dynamics during embryonic peripheral nerve development. This driver was also used to study peripheral glial anatomy during larval growth and at the mature third-instar larval neuromuscular junction and peripheral sensory structures (Sepp et al., 2000). These studies confirmed that $g l i-G a l 4$ is expressed in peripheral glia but not motor and sensory neurons.

To confirm that gli-Gal4 and MZ709 do not express Gal4 in the perineurial glia, we visualized the expression pattern of these drivers within peripheral nerves via induced expression of a nuclear-localized GFP. We also visualized the total complement of peripheral nerve nuclei (peripheral and perineurial glial) via the Hoechst DNA dye. As shown in Figure 1, $B$ and $D$, there are $\sim 20$ nuclei per millimeter of peripheral nerve. Most of these are perineurial glial nuclei, whereas a few are peripheral glial nuclei. If gli-Gal4 and MZ709 express in the perineurial glia as well as peripheral glia, then we anticipate that, in $g l i>G F P(n l s)$ and $M Z 709>G F P(n l s)$, most or all of these nuclei would contain GFP. In fact, as shown in Figure 1, $C$ and $E$, we observe that only a few (presumably peripheral glial) nuclei from these larvae express GFP. Therefore, we conclude that neither gli-Gal4 and MZ709 expresses Gal4 in the perineurial glia. We generally observe GFP in fewer than eight peripheral glial nuclei, which presumably results from cell-to-cell variability in Gal4 expression levels, as 


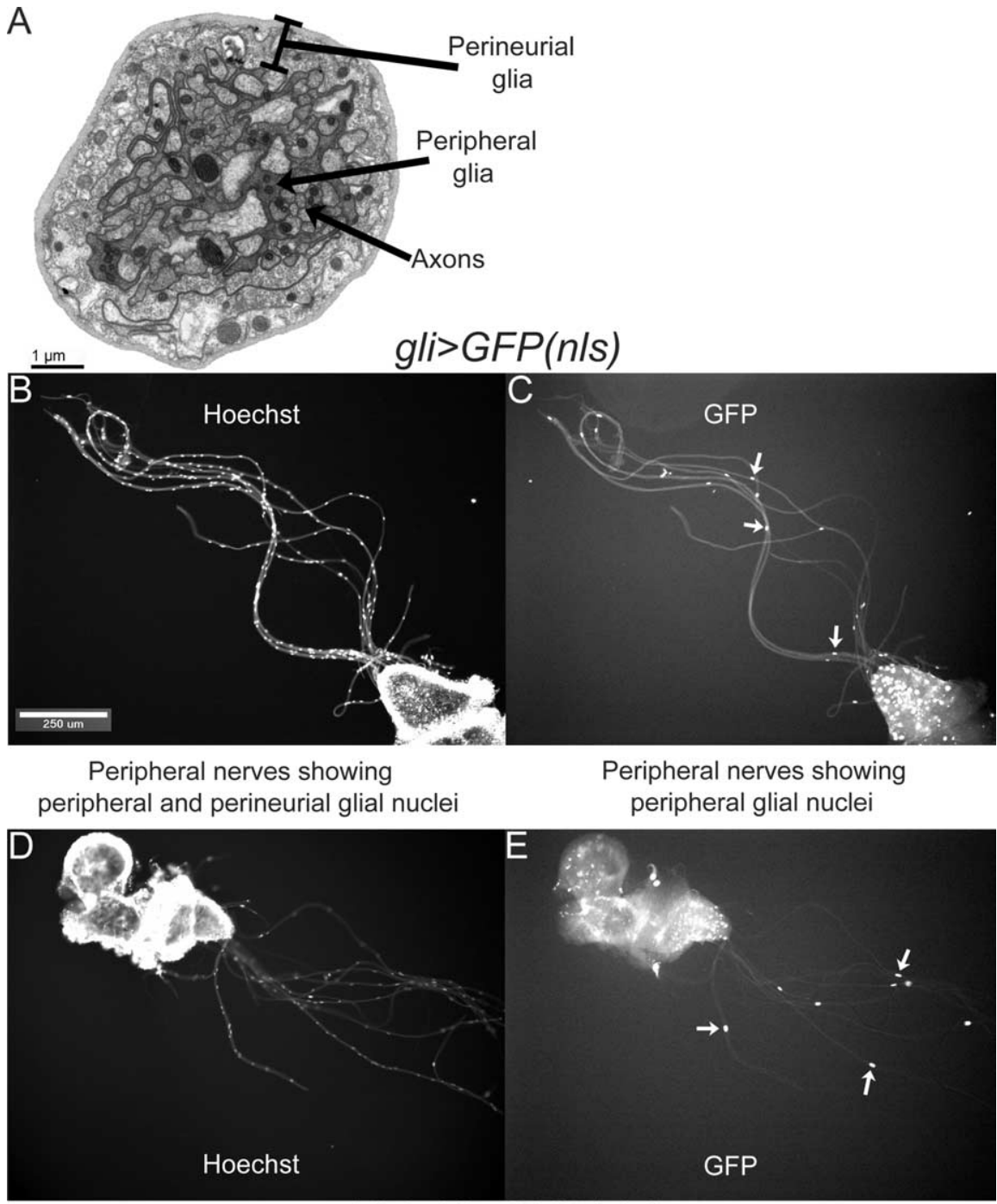

$M Z 709>G F P(n / s)$

Figure 1. gli-Gal4 and MZ709 drivers are expressed in the peripheral glia but not the perineurial glia. $A$, TEM of a cross section of a gli $>$ Ras ${ }^{+}$third-instar larval peripheral nerve of wild-type thickness. The cell types present are indicated. $B, C$, Epifluorescence images of third-instar larval peripheral nerves from $g l i>G F P(n / s)$ visualized for Hoechst and GFP, respectively. All nuclei (peripheral glial and perineurial glial) are visualized with the Hoechst stain $(\boldsymbol{B})$, whereas only a few nuclei (presumed to be peripheral glial), some marked with arrows, are visualized with GFP $(\boldsymbol{C}) \cdot \boldsymbol{D}, \boldsymbol{E}$, Same as $\boldsymbol{B}$ and $($ except that $M Z 709>\operatorname{GFP}(n / 5)$ larvae were visualized. These observations demonstrate that $g l i-G a / 4$ and $M Z 709$ are not expressed in perineurial glia.
gli-Gal4 and either of two UAS-Ras ${ }^{V 12}$ transgenes exhibited a thickened perineurial glia. The thickness observed, 2.1-2.3 $\mu \mathrm{m}$, was significantly $(\sim 50 \%)$ greater than the value observed in larvae carrying gli-Gal4 or UAS-Ras ${ }^{V 12}$ alone or gli $>$ Ras ${ }^{+}$

(Fig. 2). We conclude that Ras activation specifically within the peripheral glia is sufficient to promote perineurial glial growth. We also found that gli-Gal4driven coexpression of both UAS-Ras ${ }^{V 12}$ transgenes does not cause an additional increase in perineurial glial thickness: perineurial glial thickness in larvae expressing both transgenes is the same as in larvae expressing either transgene alone (Fig. 2). This observation suggests that, in $g l i>$ Ras $^{V 12}$ larvae, Ras $^{\text {V12 }}$ levels are not limiting for promoting perineurial glial growth. To rule out the possibility that the presence of two transgenes decreased expression of both via titration of Gal4, we measured perineurial glial thickness in larvae coexpressing Ras ${ }^{V 12}$ with an indifferent transgene (GFP). We found that this coexpression did not suppress the growthpromoting effects of Ras ${ }^{V 12}$ (Fig. 2), suggesting that the presence of a second UASdriven transgene does not significantly affect expression of the first.

\section{PI3K activation in the peripheral glia is sufficient to increase perineurial glial growth}

Activated Ras activates a number of downstream molecules, including Raf, PI3K, and the guanine nucleotide exchange factor for the Ral GTPase (Kolch et al., 1991; Rodriguez-Viciana et al., 1994; Hofer et al., 1994). To identify the effector(s) responsible for transducing the nonautonomous growth activation conferred by $R a s^{V 12}$, we expressed transgenes encoding the constitutively active Raf ${ }^{F 179}, P I 3 K-$ CAAX, and $\mathrm{Ral}^{\mathrm{V} 20}$ proteins (Brand and Perrimon, 1994; Leevers et al., 1996; Sawamoto et al., 1999) within peripheral was reported previously for peripheral glia (Sepp et al., 2001). We also observed that each driver also expresses Gal4 within certain cells of the ventral ganglion (Fig. 1).

Expression of the constitutively active Ras $^{V 12}$ allele in peripheral glia increases perineurial glial growth

In both mice and humans, neurofibroma formation appears to occur only when the Schwann cell component of the peripheral nerve is homozygous for $\mathrm{Nfl}^{-}$(Zhu et al., 2002; Kluwe et al., 1999). This observation suggests that activated Ras within Schwann cells is necessary for neurofibroma formation. To test the effects of activating Ras within Drosophila peripheral glia (analogous to the mammalian Schwann cell), we used the gliGal4 driver to express $\mathrm{Ras}^{+}$or the constitutively active Ras ${ }^{\mathrm{V} 12}$ (Bourne et al., 1991; Lee et al., 1996; Karim and Rubin, 1998) specifically in the peripheral glia. We found that larvae bearing glia using gli-Gal4. As shown in Figure 3B, we found that expression of $\mathrm{Raf}^{\mathrm{F} 179}$ or $\mathrm{Ral}^{\mathrm{V} 20}$ had no significant effect on perineurial glial thickness. However, expression of PI3K-CAAX increased perineurial glial thickness to $\sim 3 \mu \mathrm{m}$ (Fig. $3 A, B$ ). This thickness is significantly greater than both wild-type thickness and the increased thickness conferred by Ras ${ }^{V 12}$ expression. When UAS$P I 3 K-C A A X$ was expressed with a second peripheral glial driver, MZ709 (Ito et al., 1995) (Fig. 1), perineurial glial thickness was increased to the same extent as with gli-Gal4. These results suggest that Ras exerts its nonautonomous effects on perineurial glial exerts a stronger effect than $\mathrm{Ras}^{V 12}$ might indicate that PI3K levels are limiting in peripheral glia to promote perineurial glial growth. In this view, transgene-induced overexpression of PI3K$C A A X$ overcomes this limitation and enables a more robust growth effect to be observed. growth via activation of PI3K. The observation that PI3K-CAAX 


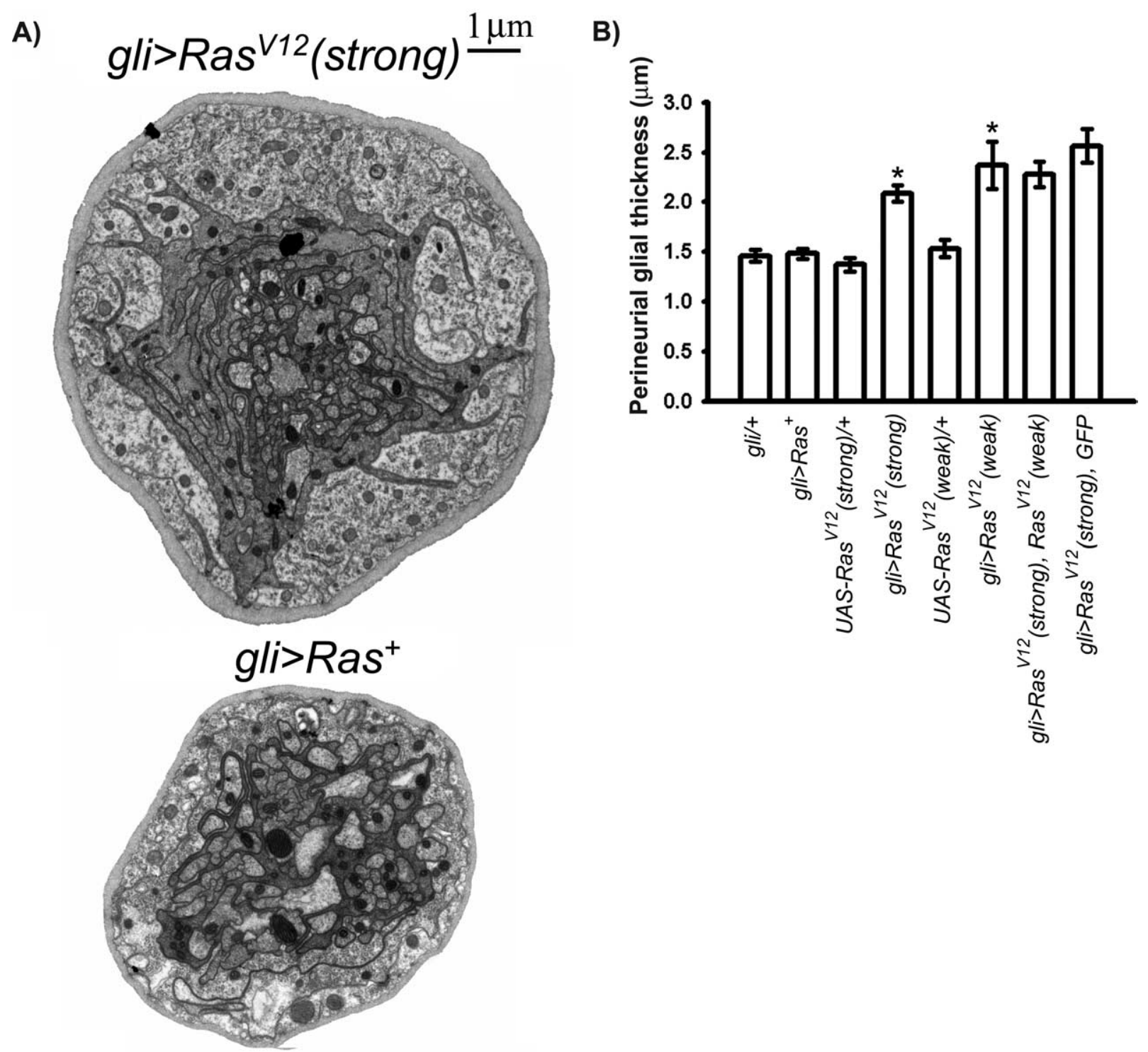

Figure 2. Expression of activated Ras in peripheral glia increases perineurial glial growth. $\boldsymbol{A}$, TEMs of cross sections from representative peripheral nerves of the indicated genotypes. The gli $>$ Ras $^{+}$nerve is the same nerve cross section shown Figure 1A. B, Perineurial glial thickness ( $y$-axis) from the indicated genotypes ( $x$-axis). Means \pm SEMs are indicated. One-way ANOVA and Scheffé's tests for multiple comparisons showed the following statistically significant differences, denoted by asterisks: gli> Ras ${ }^{V 12}$ (strong) $(2.08 \pm 0.082 \mu \mathrm{m} ; n=78), g_{i i>\text { Ras }^{V 12}}$ (weak) $(2.37 \pm$ $0.236 \mu \mathrm{m} ; n=20)$, gli $>\operatorname{Ras}^{V 12}$ (strong), Ras ${ }^{V 12}$ (weak) $(2.28 \pm 0.130 \mu \mathrm{m} ; n=56)$, and gli $>\operatorname{Ras}^{V 12}$ (strong), GFP $(2.57 \pm 0.17 \mu \mathrm{m} ; n=43)$ versus gli $>$ Ras $^{+}(1.48 \pm 0.048 \mu \mathrm{m} ; n=99)$, gli-Gal4/+ (1.46 $\pm 0.057 \mu \mathrm{m} ; n=60)$, UAS-Ras ${ }^{V 12}$ (strong)/+ $(1.37 \pm 0.068 \mu \mathrm{m} ; n=45)$, and UAS-Ras ${ }^{112}$ (weak)/ $+(1.53 \pm 0.088 \mu \mathrm{m} ; n=22)$. For all such tests, $p<0.0001$.

PI3K activity in the peripheral glia is necessary to mediate the nonautonomous, growth-promoting effect of $\operatorname{Ras}^{\mathrm{V} 12}$

The results shown in Figure 3 demonstrate that PI3K activation in peripheral glia is sufficient to increase perineurial glial growth. To determine whether PI3K activity is necessary for the nonautonomous growth-promoting effects of $\operatorname{Ras}^{V 12}$, we introduced the heteroallelic $P I 3 K$ loss-of-function combination $P I 3 K^{2 H 1} / P I 3 K^{A}$ (Halfar et al., 2001) into gli $>$ Ras $^{V 12}$ larvae. This mutant combination was chosen because it decreases PI3K activity sufficiently to confer phenotypes but retains sufficient activity to permit viability to the third-instar larval stage. We found that $P I 3 K^{2 H 1}$ / $P I 3 K^{A}$ significantly suppressed the growth-promoting effects of $\operatorname{Ras}^{V 12}$ (Fig. 4), which demonstrates that PI3K activity is necessary for this effect. To determine whether PI3K activity is necessary in peripheral glia rather than the perineurial glia, we blocked PI3K activity specifically in the peripheral glia by coexpressing
$\operatorname{Ras}^{V 12}$ with a transgene encoding the dominant-negative PI3K ${ }^{D 954 A}$ (Leevers et al., 1996). We found that the peripheralglial-specific expression of $P I 3 K^{D 954 A}$ blocked the growthpromoting effects of $\operatorname{Ras}^{V 12}$ (Fig. 4), suggesting that PI3K activity is required in the peripheral glia to promote perineurial glial growth. In contrast, as described above, coexpressing $\operatorname{Ras}^{V 12}$ with GFP did not suppress the growth-promoting effects of Ras $^{V 12}$ (Fig. 2).

To confirm that $P I 3 K^{2 H 1} / P I 3 K^{A}$ suppressed the Ras $^{V 12}$ phenotype by decreasing PI3K activity in the peripheral glia rather than the perineurial glia, we introduced $P I 3 K^{2 H 1} / P I 3 K^{A}$ into gli $>P I 3 K-C A A X$ larvae. The extremely thick perineurial glia conferred by $P I 3 K-C A A X$ was not significantly affected by the presence of $P I 3 K^{2 H 1} / P I 3 K^{A}$ (Fig. 4); thus, the perineurial glia in the $P I 3 K^{2 H 1} / P I 3 K^{A}$ mutant is fully competent to respond to growth-promoting signals from the peripheral glia, which 
A)

\section{UAS-PI3K-CAAX/+}
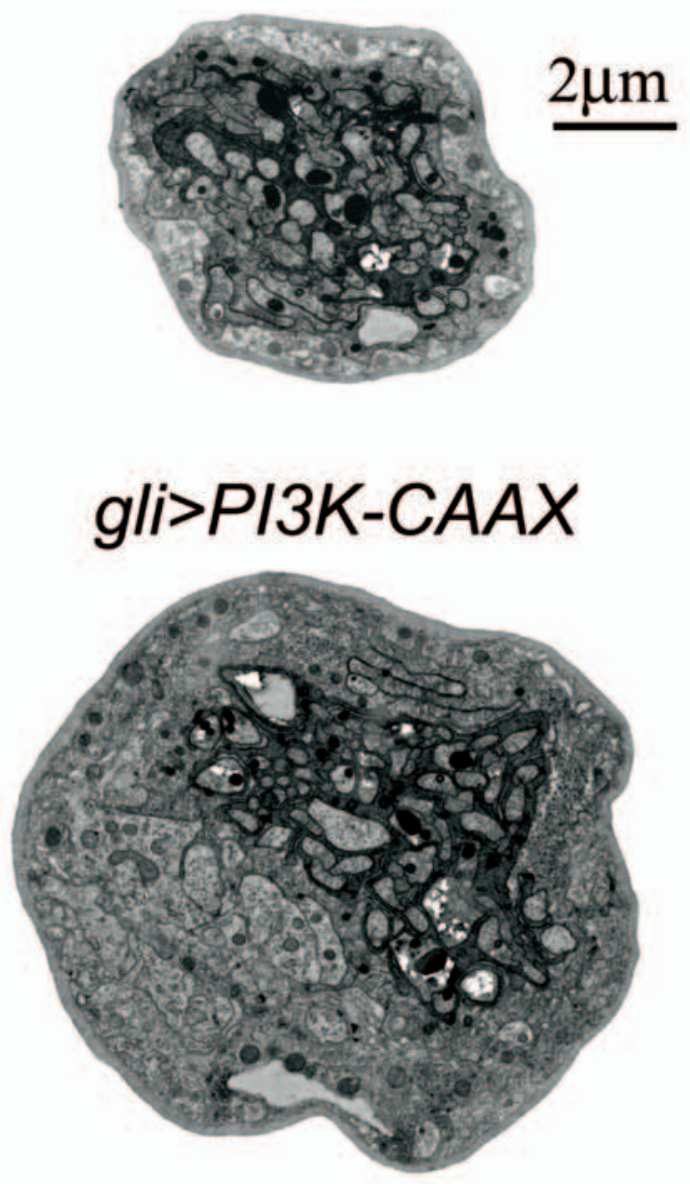

B)

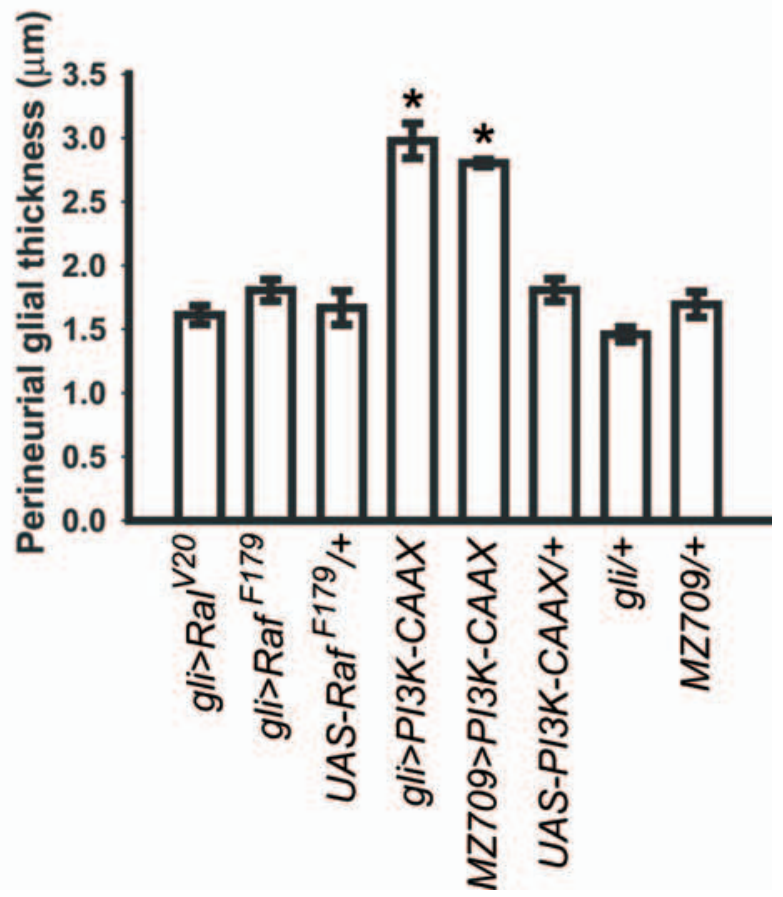

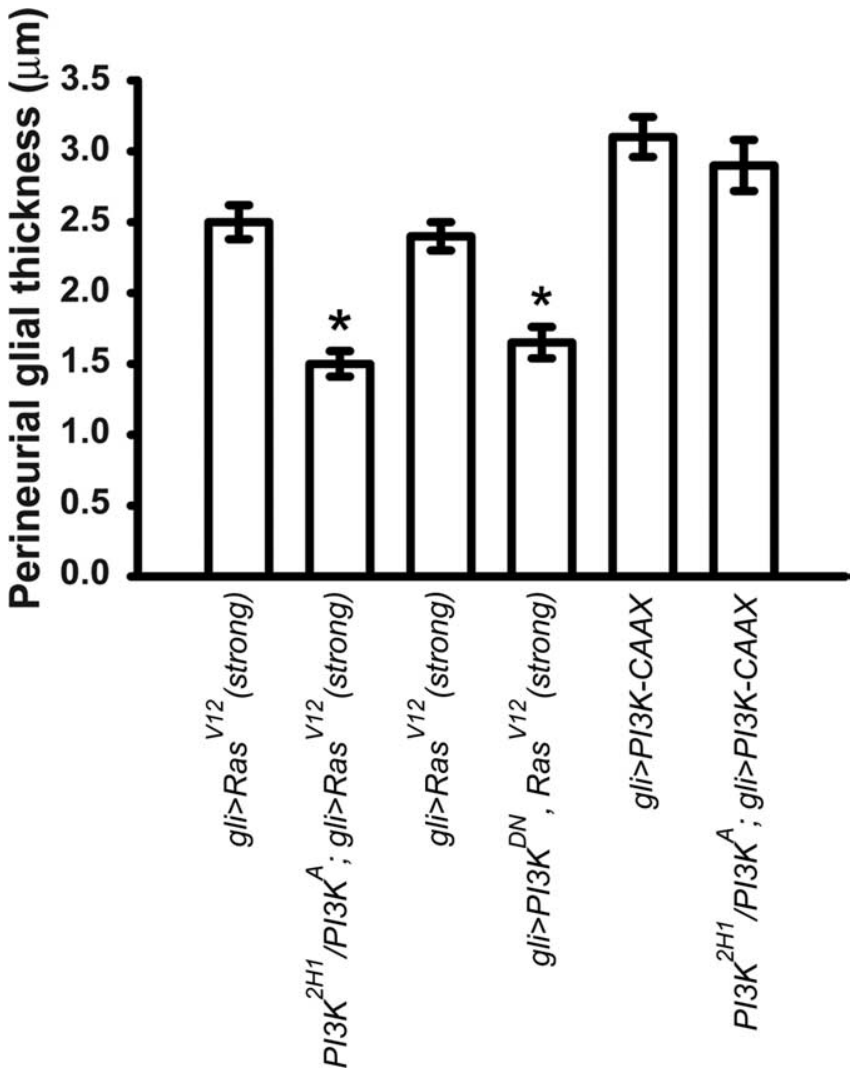

Figure 4. Ras ${ }^{12}$ requires PI3K activity in the peripheral glia to increase perineurial glial growth. Histograms show perineurial glial thickness ( $y$-axis) from the indicated genotypes ( $x$-axis). Means \pm SEMs are indicated. The increase in perineurial glial thickness observed in gli $>$ Ras $^{122}$ (lane 1 ) is significantly suppressed by the heteroallelic loss-of-function combination $P I 3 K^{2 H 1} / P I 3 K^{A}$ (lane 2). The gli $>$ Ras $^{V 12}$ larvae analyzed for lane 1 were obtained from the $P I 3 K^{+}$recombinants when PI3K $K^{A}$ was crossed onto UAS-Ras ${ }^{V 12}$, whereas the $P I 3 K^{2 H 1} / P I 3 K^{A}$; gli $>$ Ras $^{V 12}$ larvae analyzed were obtained from the PI $3 K^{A}$ recombinants from this cross; thus, the values for the genotypes shown in lanes 1 and 2 are paired. The following pairwise combinations had statistically significant differences (two-tailed, unpaired $t$ test) denoted by asterisks: gli $>$ Ras $^{V 12}$ (strong) (lane $1 ; 2.46 \pm 0.13 \mu \mathrm{m} ; n=50$ ) versus PI3K ${ }^{2 H 1} / P I 3 K^{A} ;$ gli $>$ Ras $^{V 12}$ $(1.54 \pm 0.05 \mu \mathrm{m} ; n=85), p<0.0001 ;$ for gli $>$ Ras $^{V 12}$ (strong) (lane 3; $2.41 \pm 0.111 \mu \mathrm{m}$; $n=72$ ) versus gli $>\operatorname{Ras}^{112}$ (strong), PI3K $K^{0554 A}(1.75 \pm 0.08 \mu \mathrm{m} ; n=49), p<0.0001$. In contrast, gli>PI3K-CAAX (3.1 $\pm 0.14 \mu \mathrm{m} ; n=53)$ was not significantly different from $P I 3 K^{2 H 1} /$ PI3K $;$ gli $>$ PI3K-CAAX $(2.88 \pm 0.35 \mu \mathrm{m} ; n=11), p=0.43$

strongly suggests that the significant suppression of the $\operatorname{Ras}^{V 12}$ growth phenotype by PI3K $K^{2 H 1} /$ PI3K $K^{A}$ results from loss of PI3K activity in the peripheral glia.

The PI3K effector Akt mediates the nonautonomous effects of $\mathrm{PI} 3 \mathrm{~K}$ on perineurial glial growth

One PI3K effector is the protein kinase Akt (Scheid and Woodgett, 2001). Elevated PI3K activity promotes the ability of

\footnotetext{
Figure 3. Peripheral glial activity of constitutively active PI3K, but not constitutively active Ral or Raf, is sufficient to increase perineurial glial growth. $A$, TEMs of cross sections from representative peripheral nerves of the indicated genotypes. $\boldsymbol{B}$, Perineurial glial thickness ( $y$ axis) from the indicated genotypes ( $X$-axis). Means \pm SEMs are indicated. One-way ANOVA and Scheffe's tests for multiple comparisons showed the following statistically significant differences, denoted by asterisks: gli $>$ PI3K-CAAX $(2.98 \pm 0.136 \mu \mathrm{m} ; n=76)$ and MZ709 $>$ PI3KCAAX $(2.80 \pm 0.263 \mu \mathrm{m} ; n=33)$ versus UAS-PI3K-CAAX/+ $(1.81 \pm 0.088 \mu \mathrm{m} ; n=59)$, gli-Gal4/+ (1.46 $\pm 0.057 \mu \mathrm{m} ; n=60)$ and MZ709/+ (1.69 $\pm 0.10 \mu \mathrm{m} ; n=27)$. For all such tests, $p<0.0001$. In contrast, $g l i>$ Raf $^{f 179}$ and $g / i>$ Ral $^{120}$ showed no significant increase in perineurial glial thickness.
} 
the kinase PI3K-dependent kinase PDK1 to phosphorylate and activate Akt. To determine whether Akt activity was necessary for the growth-promoting effects of PI3K, we replaced either one or both copies of $A k t^{+}$with the strong hypomorphic $A k t^{4226}$ allele (Perrimon et al., 1996) in gli $>P I 3 K-C A A X$ larvae. We found that replacing one copy of $A k t^{+}$moderately suppressed, and replacing both copies of $\mathrm{Akt}^{+}$ profoundly suppressed, the effects of $P I 3 K-C A A X$ (Fig. 5). These results demonstrate that Akt activity is required for the growth-promoting effects of PI3K. Akt activity can promote growth cell autonomously (Hay and Sonenberg, 2004). Thus, $A k t^{4226}$ could suppress the growthpromoting effects of $P I 3 K-C A A X$ by decreasing Akt activity in either the peripheral or perineurial glia. To determine whether $A k t^{+}$activity in the peripheral glia was sufficient to increase perineurial glial growth, we measured perineurial glial thickness in larvae expressing either of two $U A S-A k t^{+}$transgenes driven by gli-Gal4 and found no effect on the perineurial glia (Fig. 5). Because these $\mathrm{Akt}^{+}$transgenes encode wild-type Akt, which requires activation by the PI3K-dependent kinase PDK1, it was possible that this lack of effect might result from low endogenous PI3K activity in the peripheral glia, which would lead to inability to activate Akt. To test this possibility, we activated Akt in the peripheral glia by using gli-Gal4 to cooverexpress UAS-Akt ${ }^{+}$with UAS-PI3K$C A A X$. We found a striking increase in perineurial glial thickness in this genotype compared with larvae overexpressing $P I 3 K-C A A X$ alone (Fig. 5; note that the $g l i>P I 3 K-C A A X, A k t^{+}$nerve pictured is an extreme nerve, not a typical nerve). This result suggests that, in the presence of activated PI3K, Akt levels within the peripheral glia become limiting for activating growth nonautonomously. In this view, increasing Akt levels by transgene expression serves to relieve this limitation and enable an additional increase in perineurial glial growth. We conclude that Akt activation in the peripheral glia is sufficient to increase perineurial glial growth.

In addition to the effect of $g l i>P I 3 K-C A A X, A k t$ on perineurial glial thickness, we observed a significant increase in thickness of the "axon bundle" (motor and sensory axons and peripheral glia) in this genotype. This increased thickness is attributable mostly to the presence of motor and sensory axons of increased diameter (Fig. 5). A more complete description of this phenotype will be presented in a future study. However, these observations suggest that extremely high levels of Akt activity can nonautonomously activate axonal growth as well as perineurial glial growth.

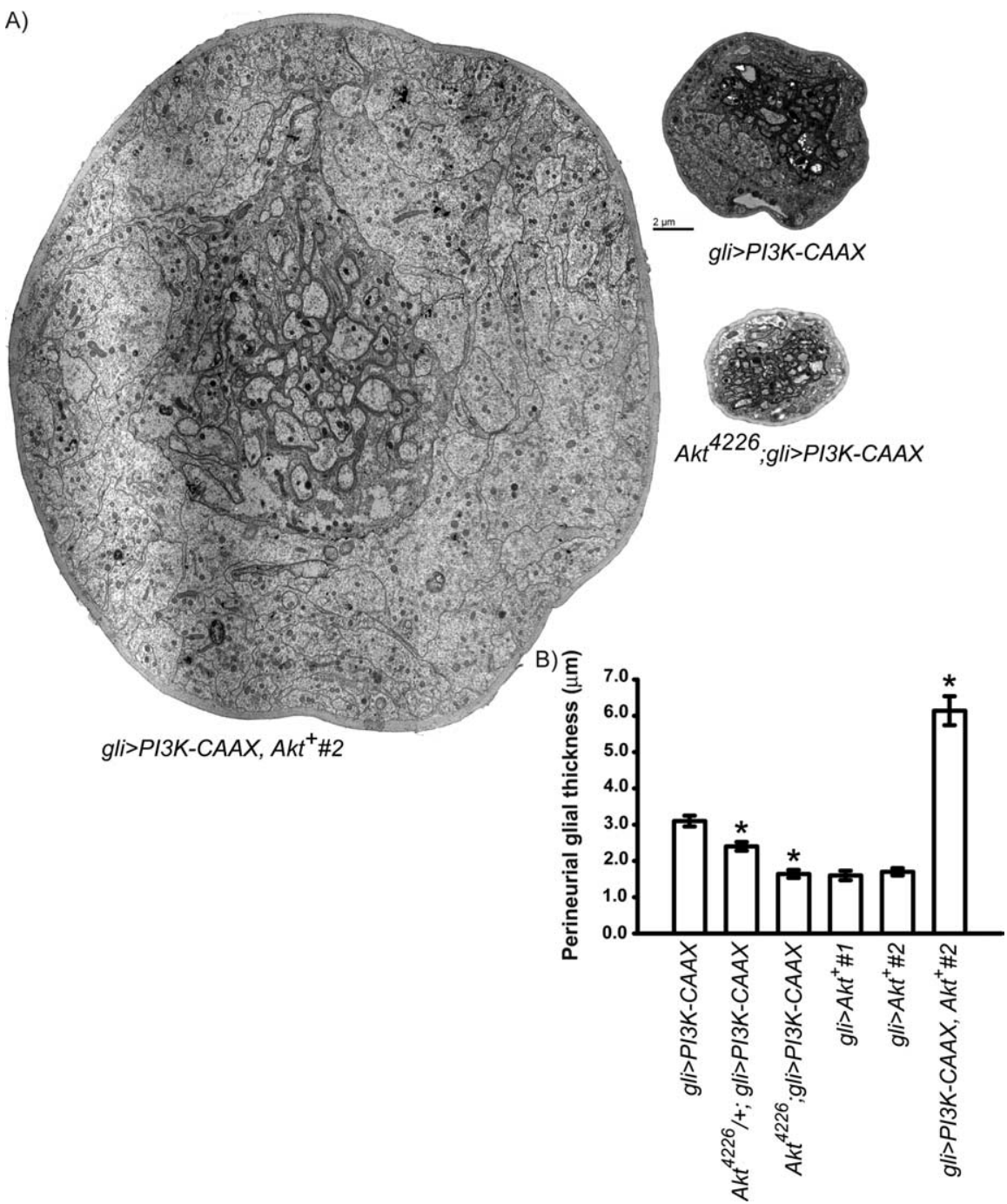

Figure 5. Akt activity in the peripheral glia is necessary and sufficient for PI3K-induced nonautomous growth activation. $\boldsymbol{A}$, TEMs of cross sections from peripheral nerves of the indicated genotypes. The gli $>$ PI3K-CAAX, $\mathrm{Akt}^{+} \# 2$ nerve was too large to be photographed in a single electron micrograph, and thus a photo montage composed of four separate photographs is shown. This nerve is not typical and represents one of the larger nerves of this genotype. The same gli $>P I 3 K-C A A X$ nerve from Figure 3 is shown for relative comparison with perineurial glial thickness of other genotypes. $B$, Perineurial glial thickness ( $y$-axis) from the indicated genotypes ( $x$-axis). Means \pm SEMs are indicated. One-way ANOVA and Scheffé's tests for multiple comparisons showed the following statistically significant differences, denoted by asterisks: gli $>$ PI3K-CAAX $(2.98 \pm 0.136 \mu \mathrm{m} ; n=76)$ versus $A_{k t} t^{4226} /+; g l i>P I 3 K-C A A X(2.42 \pm 0.16 \mu \mathrm{m} ; n=29), p=0.02$, and versus $A k t^{4226} /$ Akt $^{4226} ;$ gli $>$ PI3K-CAAX $(1.65 \pm 0.42$ $\mu \mathrm{m} ; n=52), p<0.0001$. Also, gli $>$ PI3K-CAAX, Akt ${ }^{+} \# 2$ (6.14 $\left.\pm 0.45 \mu \mathrm{m} ; n=28\right)$ versus gli $>$ PI3K-CAAX, gli $>A k t^{+} \# 1$ $(1.48 \pm 0.057 \mu \mathrm{m} ; n=32)$ and $g l i>A k t^{+} \# 2(1.52 \pm 0.068 \mu \mathrm{m} ; n=22), p<0.0001$. UAS $-A k t^{+} \# 1$ and UAS-Akt ${ }^{+}$2 are independent insertions of the same transgene.

\section{FOXO overexpression suppresses the growth-promoting effects of PI3K}

One Akt effector is the forkhead-box transcription factor FOXO. FOXO inhibits PI3K- and Akt-dependent gene expression; this activity is lost during phosphorylation by Akt, which causes phospho-FOXO to be excluded from the nucleus (Brunet et al., 1999). To test the possibility that PI3K and Akt activity increase perineurial glial growth by inhibiting FOXO, we coexpressed PI3K-CAAX and either of two FOXO transgenes (Hwangbo et al., 2004) within the peripheral glia. We found that expression of either FOXO transgene significantly suppressed the growthpromoting effects of $P I 3 K-C A A X$ (Fig. 6). In contrast, when we coexpressed $P I 3 K-C A A X$ with a neutral $U A S$-driven transgene (UAS-GFP), we did not observe significant suppression (Fig. 6). 


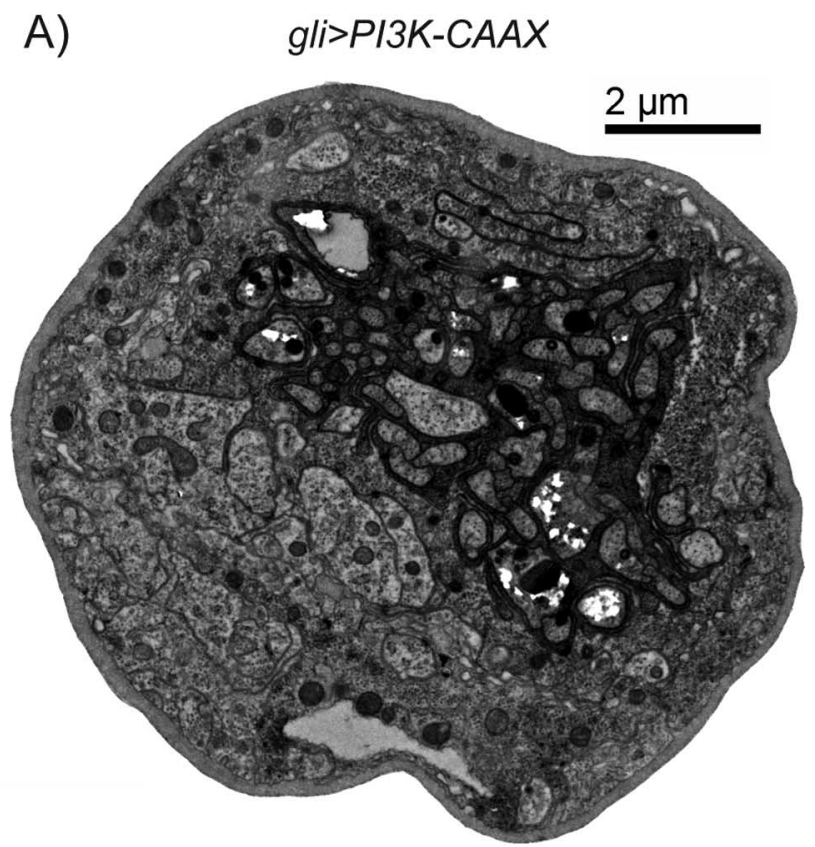

gli>PI3K-CAAX, FOXO' ${ }^{+}(119-5)$
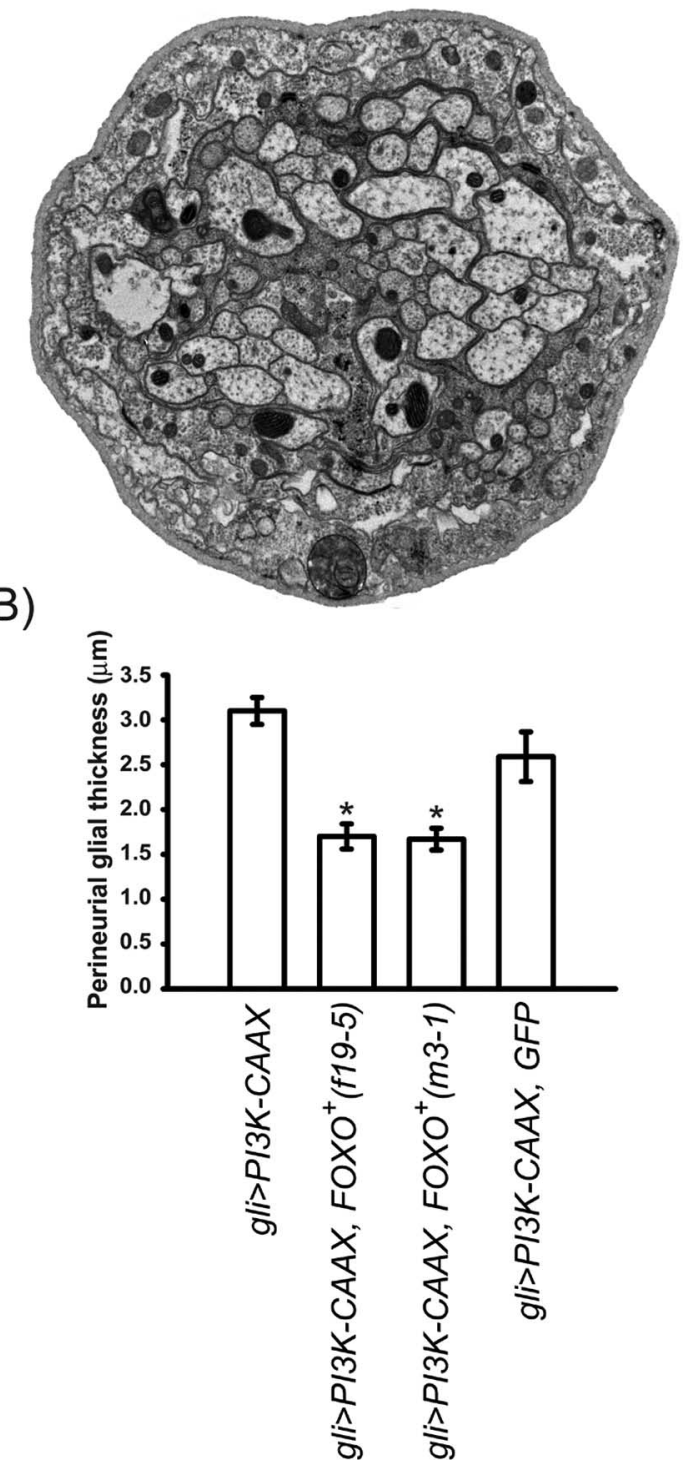

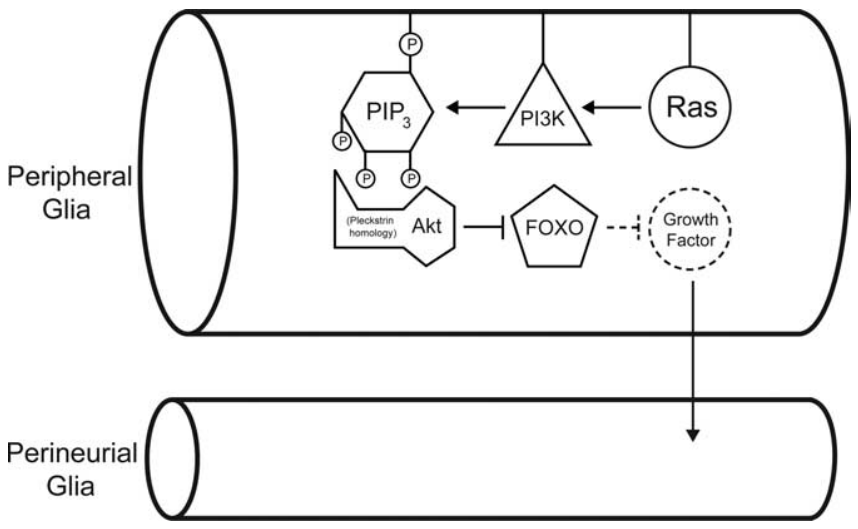

Figure 7. Model for the nonautonomous control of perineurial glial growth by the PI3K pathway. Peripheral and perineurial glial cells are indicated. The experimental evidence reported here demonstrates that Ras-PI3K-Akt activity in the peripheral glia increases growth of the perineurial glia and suggests that this activation occurs by the inhibition of FOXO (solid arrows and boxes). We hypothesize (dashed arrows and boxes) that FOX0 directly or indirectly inhibits expression of a growth factor that activates perineurial glial cell growth. $\mathrm{PIP}_{3}$, Phosphatidylinositol $(3,4,5)$-trisphosphate; $P$, phosphate.

Thus, FOXO overexpression suppresses the growth-promoting effects of PI3K.

Our studies provide new mechanistic insights into the nonautonomous growth-promoting effects of peripheral glia (Schwann cells) in peripheral nerves. Our results are completely consistent with the possibility that these nonautonomous effects are mediated by a pathway in which the negative regulation of growth by FOXO is inhibited by its Akt-dependent phosphorylation. FOXO might directly or indirectly repress transcription of growth factors that recruit the growth of neighbors.

\section{Discussion}

We report the effects of altered activity of Ras and downstream effectors on growth within Drosophila peripheral nerves. We found that activating Ras specifically within the peripheral glia was sufficient to increase growth of the perineurial glia. In addition, we found that activating the Ras effector PI3K (RodriguezViciana et al., 1994), but not Raf or Ral, within the peripheral glia was sufficient to increase perineurial glial growth and that inhibiting PI3K activity in the peripheral glia, but not perineurial glia, suppressed the growth-promoting effects of activated Ras. We also found that activity within the peripheral glia of the PI3Kactivated kinase Akt (Franke et al., 1995; Scheid and Woodgett, 2001) was both necessary and sufficient to mediate the growthpromoting effects of PI3K. Finally, we found that overexpression within the peripheral glia of FOXO, the forkhead-box transcription factor that is phosphorylated and inactivated by Aktdependent phosphorylation (Brunet et al., 1999), was sufficient to suppress the growth-promoting effects of PI3K. Together,

$\leftarrow$

Figure 6. PI3kinase and Akt increase perineurial glial growth by inhibition of FOXO. A, TEMs of cross sections from peripheral nerves of the indicated genotypes. The same gli-PI3K-CAAX nerve from Figure 3 is shown for relative comparison of perineurial glial thickness to gli $>P I 3 K-$ $\mathrm{CAAX}, \mathrm{FOXO}^{+}(\mathrm{f19}-5)$ nerve. $B$, Perineurial glial thickness ( $y$-axis) from the indicated genotypes $(x$-axis). Means \pm SEMs are indicated. One-way ANOVA and Scheffé's tests for multiple comparisons showed the following statistically significant differences, denoted by asterisks: gli $>$ PI3K-CAAX $(2.98 \pm 0.136 \mu \mathrm{m} ; n=76)$ and gli $>$ PI3K-CAAX, GFP $(2.59 \pm 0.28 \mu \mathrm{m}$; $n=25)$ versus gli $>P I 3 K-C A A X, F_{X X O}^{+}(f 19-5)(1.67 \pm 0.086 \mu \mathrm{m} ; n=30), p<0.004$, and versus gli $>$ PI3K-CAAX, FOXO ${ }^{+}(\mathrm{m3}-1)(1.70 \pm 0.098 \mu \mathrm{m} ; n=64), p<0.01$. UAS$\mathrm{FOXO}^{+}$(f19-5) and $\mathrm{UAS}_{-} \mathrm{FOXO}^{+}(\mathrm{m3}-1)$ are independent insertions of the same transgene. 
these results suggest that Ras activity in the peripheral glia activates nonautonomous growth via the PI3K and Akt-dependent inhibition of FOXO (Fig. 7). This observation is consistent with the previous observations that $\mathrm{NI}^{-}$mouse Schwann cells oversecrete growth factor(s) that cause increased recruitment of mast cells into the peripheral nerve (Yang et al., 2003) and is consistent in part with the observation that the proliferation defects of $\mathrm{Nf1}^{-}$ mutant mouse or human cells requires hyperactivation of Tor in a PI3K- and Akt-dependent manner (Dasgupta et al., 2005; Johannessen et al., 2005).

\section{Regulation of peripheral nerve growth by a neuron-glia signaling pathway}

Yager et al. (2001) reported that perineurial glial growth in Drosophila peripheral nerves is regulated by several genes. These genes include Nf1, which is the Drosophila ortholog of human $N f 1$, push, which is thought to encode an E3 ubiquitin ligase and two genes implicated in neurotransmitter signaling: amnesiac, which is thought to encode a neuropeptide similar to vertebrate pituitary adenylate cyclase-activating polypeptide (Feany and Quinn, 1995), and inebriated (ine), which encodes a member of the $\mathrm{Na}^{+} / \mathrm{Cl}^{-}$-dependent neurotransmitter transporter family (Soehnge et al., 1996). Some of these genes might regulate perineurial glial growth via the activity of Ras or PI3K within peripheral glia. For example, mutations in push, but not ine, enhance the perineurial glial growth phenotype of $\operatorname{Ras}^{V 12}$ expressed in peripheral glia (Lavery and Stern, unpublished observations). These observations are consistent with the possibility that the activity of ine regulates Ras-GTP levels within peripheral glia. In contrast, push might regulate PI3K in a Ras-independent manner or act in the perineurial glia to regulate sensitivity to peripheral glial growth factors. Additional experiments will be required to distinguish between these possibilities.

\section{Regulation of peripheral nerve growth by Schwann cell nonautonomous mechanisms}

There are several lines of evidence from mice and humans suggesting that cell nonautonomous growth regulation, as a consequence of intercellular signaling, underlies neurofibroma formation. First, although neurofibromas arise in individuals heterozygous for $\mathrm{Nf1}^{-}$after loss of $\mathrm{Nfl}^{+}$from cell(s) within peripheral nerves, neurofibromas are heterogeneous and contain cells that are not clonally related, such as Schwann cells, perineurial cells, and fibroblasts. These observations suggest that neurofibromas arise when a core of $\mathrm{Nf1}^{-}$ cells cause overproliferation of their heterozygous neighbors via nonautonomous means. Second, neurofibroma formation in mice and humans requires a homozygous $N f 1$ mutant genotype in Schwann cells but not other cells within the tumor (Kluwe et al., 1999; Zhu et al., 2002). Third, Ras-GTP levels in Schwann cells from the mouse $N f 1$ knock-out mutant are uniformly elevated. In contrast, only a subset of Schwann cells from human neurofibromas exhibit elevated Ras- GTP levels (Sherman et al., 2000); these authors raised the possibility that this subset, but not other Schwann cells from the tumor, was homozygous for $\mathrm{Nf1}^{-}$. In this view, these $\mathrm{Nf1} 1^{-}$cells recruited neighboring Schwann cells that were heterozygous for $\mathrm{Nf1}^{-}$ into the tumor by nonautonomous means, such as by the excessive release of one or more growth factors. Fourth, Yang et al. (2003) demonstrated that $\mathrm{Nf}^{-}$Schwann cells oversecrete the ligand for the $\mathrm{c}$-Kit receptor. This oversecretion increased migration of mast cells into peripheral nerves and might be an essential step in neurofibroma formation. These Schwann cells also oversecrete additional factors whose physiological role remains unclear (Yang et al., 2003). The molecular mechanisms by which neurofibromin regulates the synthesis or release of these molecules remain incompletely understood. Our observations that Ras activity in the peripheral glia promotes growth nonautonomously via the PI3Kand Akt-dependent inhibition of FOXO might provide insights into the mechanisms by which peripheral nerve growth is regulated nonautonomously by the mammalian Schwann cell.

\section{Regulation of peripheral nerve growth by Ras effectors}

By hyperactivating Ras, Nf1 mutations could in principle cause tumors via any of several Ras effector pathways. In addition, the diverse types of tumors observed in individuals with neurofibromatosis (for review, see Cichowski and Jacks, 2001) could result from hyperactivation of distinct Ras effector pathways. The Raf pathway has been viewed previously as a more relevant effector pathway than the PI3K pathway, mostly because the importance of Ras in the activation of PI3K under physiological conditions remains controversial. In particular, although it is clear that the oncogenic Ras ${ }^{V 12}$ mutant is sufficient to activate PI3K (Rodriguez-Viciana et al., 1994), it has sometimes been difficult to demonstrate that wild-type Ras is necessary for PI3K activation (Prober and Edgar, 2002). Presumably, this difficulty reflects the fact that PI3K can be activated by Ras-independent as well as Ras-dependent mechanisms, such as direct activation by activated receptor tyrosine kinases or by PIKE-L (phosphatidylinositol kinase enhancer) (Escobedo et al., 1991; Rong et al., 2004). However, more recently, it has been demonstrated that PI3K and Akt are hyperactivated in several $N f 1$ mutant cell types and that this hyperactivation is Ras dependent (Dasgupta et al., 2005; Johannessen et al., 2005). Furthermore, PI3K activation plays an essential functional role in $\mathrm{Nf1}^{-}$-mediated growth defects, as was demonstrated by the observation that PI3K- and Akt-dependent Tor activation was necessary for the proliferation defects of $\mathrm{Nf1}$ mutants to occur: application of rapamycin, a Tor inhibitor, attenuated the ability of $N f 1$ mutant cells to proliferate (Johannessen et al., 2005). These observations demonstrate that PI3K and Akt play key roles in at least some aspects of $\mathrm{Nf1}^{-}$-induced tumor growth.

Our results are consistent with these observations. By comparing the effects on perineurial glial growth of peripheralglial expression of activated Raf, PI3K, or Ral, we were able to demonstrate that activation of PI3K, not Raf or Ral, was sufficient to promote perineurial glial growth and that PI3K activity in the peripheral glia was necessary to observe the nonautonomous effect of activated Ras on perineurial glial growth. We similarly showed that Akt activity was necessary and sufficient to mediate the growth-promoting effects of PI3K. However, whereas Dasgupta et al. (2005) and Johannessen et al. (2005) observed that Tor activation was critical for the PI3K- and Akt-dependent growth regulation of $\mathrm{Nf1}$ mutant cells, we observed a critical role for the PI3K- and Aktdependent inhibition of the transcription factor FOXO. It is possible that the phenotype observed by Dasgupta et al. (2005) and Johannessen et al. (2005) reflects the well characterized ability of PI3K-Tor to activate growth cell autonomously (Hay and Sonenberg, 2004), whereas the phenotype we report reflects nonautonomous growth regulation. In this view, PI3K and Akt regulate autonomous and nonautonomous growth via the Tor and FOXO pathways, respectively. 
FOXO presumably inhibits the growth-promoting effects of PI3K and Akt by transcriptional regulation of target genes. Candidate FOXO target genes include those encoding the molecules oversecreted by $\mathrm{Nfl}^{-}$Schwann cells (Yang et al., 2003), whereas other targets might be represented in the distinct transcript profiles exhibited by $\mathrm{Nf}^{-}$Schwann cells (Mashour et al., 2001) or malignant peripheral nerve sheath tumors (Miller et al., 2006) compared with wild-type Schwann cells. For example, Schwann cells from neurofibromas, but not normal Schwann cells, express the epidermal growth factor (EGF) receptor (DeClue et al., 2000). Other potential targets include genes encoding growth factors, although ectopic expression within the peripheral glia of two candidate genes, Hedgehog and the EGF ligands spitz and gurken, failed to induce perineurial glial growth (Lavery and Stern, unpublished observation). Additional experiments will be required to identify the FOXO targets that regulate nonautonomous growth in peripheral nerves.

\section{References}

Auld VJ, Fetter RD, Broadie K, Goodman CS (1995) Gliotactin, a novel transmembrane protein on peripheral glia, is required to form the bloodnerve barrier in Drosophila. Cell 81:757-767.

Bourne HR, Sanders DA, McCormick F (1991) The GTPase superfamily: conserved structure and molecular mechanism. Nature 349:117-127.

Brand A, Perrimon N (1993) Targeted gene expression as a means of altering cell fates and generating dominant phenotypes. Development 118:401-415.

Brand AH, Perrimon N (1994) Raf acts downstream of the EGF receptor to determine dorsoventral polarity during Drosophila oogenesis. Genes Dev $8: 629-639$.

Brunet A, Bonni A, Zigmond MJ, Lin MZ, Juo P, Hu LS, Anderson MJ, Arden KC, Blenis J, Greenberg ME (1999) Akt promotes cell survival by phosphorylating and inhibiting a forkhead transcription factor. Cell 96:857-868.

Cichowski K, Jacks T (2001) NF1 tumor suppressor gene function: narrowing the GAP. Cell 104:593-604.

Colomar A, Robitaille R (2004) Glial modulation of synaptic transmission at the neuromuscular junction. Glia 47:284-289.

Dasgupta B, Yi Y, Chen DY, Weber JD, Gutmann DH (2005) Proteomic analysis reveals hyperactivation of the mammalian target of rapamycin pathway in neurofibromatosis 1-associated human and mouse brain tumors. Cancer Res 65:2755-2760.

DeClue JE, Heffelfinger S, Benvenuto G, Ling B, Li S, Rui W, Vass WC, Viskochil D, Ratner N (2000) Epidermal growth factor receptor expression in neurofibromatosis type 1-related tumors and NF1 animal models. J Clin Invest 105:1233-1241.

Edwards JS, Swales LS, Bate M (1993) The differentiation between neuroglia and connective tissue sheath in insect ganglia revisited: the neural lamella and perineurial sheath cells are absent in a mesodermless mutant of Drosophila. J comp Neurol 333:301-308.

Escobedo JA, Navankasattusas S, Kavanaugh WM, Milfay D, Fried VA, Williams LT (1991) cDNA cloning of a novel $85 \mathrm{kd}$ protein that has $\mathrm{SH} 2$ domains and regulates binding of PI3-kinase to the PDGF beta-receptor. Cell 65:75-82.

Feany MB, Quinn WG (1995) A neuropeptide gene defined by the Drosophila memory mutant amnesiac. Science 268:869-873.

Franke TF, Yang SI, Chan TO, Datta K, Kazlauskas A, Morrison DK, Kaplan DR, Tsichlis PN (1995) The protein kinase encoded by the Akt protooncogene is a target of the PDGF-activated phosphatidylinositol 3-kinase. Cell 81:727-736.

Halfar K, Rommel C, Stocker H, Hafen E (2001) Ras controls growth, survival and differentiation in the Drosophila eye by different thresholds of MAP kinase activity. Development 128:1687-1696.

Hay N, Sonenberg N (2004) Upstream and downstream of mTOR. Genes Dev 18:1926-1945.

Hofer F, Fields S, Schneider C, Martin GS (1994) Activated Ras interacts with the Ral guanine nucleotide dissociation stimulator. Proc Natl Acad Sci USA 91:11089-11093.

Hwangbo DS, Gersham B, Tu MP, Palmer M, Tatar M (2004) Drosophila
$\mathrm{dFOXO}$ controls lifespan and regulates insulin signalling in brain and fat body. Nature 429:562-566.

Ito K, Urban J, Technau GM (1995) Distribution, classification, and development of Drosophila glial cells in late embryonic ventral nerve cord. Rouxs Arch Dev Biol 204:284-307.

Johannessen CM, Reczek EE, James MF, Brems H, Legius E, CichowskI K (2005) The NF1 tumor suppressor critically regulates TSC2 and mTOR. Proc Natl Acad Sci USA 102:8573-8578.

Junger MA, Rintelen F, Stocker H, Wasserman JD, Vegh M, Radimerski T, Greenberg ME, Hafen E (2003) The Drosophila forkhead transcription factor FOXO mediates the reduction in cell number associated with reduced insulin signaling. J Biol 2:20.

Karim FD, Rubin GM (1998) Ectopic expression of activated Ras1 induces hyperplastic growth and increased cell death in Drosophila imaginal tissues. Development 125:1-9.

Kluwe L, Friedrich R, Mautner VF (1999) Loss of NF1 allele in Schwann cells but not in fibroblasts derived from an NF1-associated neurofibroma. Genes Chromosomes Cancer 24:283-285.

Kolch W, Heidecker G, Lloyd P, Rapp UR (1991) Raf-1 protein kinase is required for growth of induced NIH/3T3 cells. Nature 349:426-428.

Lee T, Feig L, Montell DJ (1996) Two distinct roles for Ras in a developmentally regulated cell migration. Development 122:409-418.

Leevers SJ, Weinkove D, MacDougall LK, Hafen E, Waterfield MD (1996) The Drosophila phosphoinositide 3-kinase Dp110 promotes cell growth. EMBO J 15:6584-6594.

Leiserson WM, Harkins EW, Keshishian H (2000) Fray, a Drosophila serine/ threonine kinase homologous to mammalian PASK, is required for axonal ensheathment. Neuron 28:793-806.

Mashour GA, Ratner N, Khan GA, Wang HL, Martuza RL, Kurtz A (2001) The angiogenic factor midkine is aberrantly expressed in NF1-deficient Schwann cells and is a mitogen for neurofibroma-derived cells. Oncogene 20:97-105.

Miller SJ, Rangwala F, Williams J, Ackerman P, Kong S, Jegga AG, Kaiser S, Aronow BJ, Frahm S, Kluwe L, Mautner V, Upadhyaya M, Muir D, Wallace M, Hagen J, Quelle DE, Watson MA, Perry A, Gutmann DH, Ratner N (2006) Large-scale molecular comparison of human schwann cells to malignant peripheral nerve sheath tumor cell lines and tissues. Cancer Res 66:2584-2591.

Parmantier E, Lynn B, Lawson D, Turmaine M, Namini SS, Chakrabarti L, McMahon AP, Jessen KR, Mirsky R (1999) Schwann cell-derived Desert hedgehog controls the development of peripheral nerve sheaths. Neuron 23:713-724.

Perrimon N, Lanjuin A, Arnold C, Noll E (1996) Zygotic lethal mutations with maternal effect phenotypes in Drosophila melanogaster. II. Loci on the second and third chromosomes identified by P-element-induced mutations. Genetics 144:1681-1692.

Prober DA, Edgar BA (2002) Interactions between Ras1, dMyc, and dPI3K signaling in the developing Drosophila wing. Genes Dev 16:2286-2299.

Puig O, Marr MT, Ruhf ML, Tjian R (2003) Control of cell number by Drosophila FOXO: downstream and feedback regulation of the insulin receptor pathway. Genes Dev 17:2006-2020.

Rodriguez-Viciana P, Warne PH, Dhand R, Vanhaesebroeck B, Gout I, Fry MJ, Waterfield MD, Downward J (1994) Phosphatidylinositol-3-OH kinase as a direct target of Ras. Nature 370:527-532.

Rong R, Tang X, Gutmann DH, Ye K (2004) Neurofibromatosis 2 (NF2) tumor suppressor merlin inhibits phosphatidylinositol 3-kinase through binding to PIKE-L. Proc Natl Acad Sci USA 101:18200-18205.

Sawamoto K, Winge P, Koyama S, Hirota Y, Yamada C, Miyao S, Yoshikawa S, Jin MH, Kikuchi A, Okano H (1999) The Drosophila Ral GTPase regulates developmental cell shape changes through the Jun $\mathrm{NH}_{2}$-terminal kinase pathway. J Cell Biol 146:361-372.

Scheid MP, Woodgett JR (2001) PKB/AKT: functional insights from genetic models. Nat Rev Mol Cell Biol 2:760-768.

Sepp KJ, Auld VJ (1999) Conversion of lacZ enhancer trap lines to GAL4 lines using targeted transposition in Drosophila melanogaster. Genetics 151:1093-1101.

Sepp KJ, Schulte J, Auld VJ (2000) Developmental dynamics of peripheral glia in Drosophila melanogaster. Glia 30:122-135.

Sepp KJ, Schulte J, Auld VJ (2001) Peripheral glia direct axon guidance across the CNS/PNS transition zone. Dev Biol 238:47-63.

Serra E, Rosenbaum T, Winner U, Aledo R, Ars E, Estivill X, Lenard HG, Lazaro C (2000) Schwann cells harbor the somatic NF1 mutation in 
neurofibromas: evidence of two different Schwann cell subpopulations. Hum Mol Genet 9:3055-3064.

Sherman LS, Atit R, Rosenbaum T, Cox AD, Ratner N (2000) Single cell RasGTP analysis reveals altered Ras activity in a subpopulation of neurofibroma Schwann cells but not fibroblasts. J Biol Chem 275:30740-30745.

Shiga Y, Tanaka-Matakatsu M, Hayashi S (1996) A nuclear GFP/ betagalactosidase fusion protein as a marker for morphogenesis in living Drosophila. Dev Growth Differ 38:99-106.

Soehnge H, Huang X, Becker M, Whitley P, Conover D, Stern M (1996) A neurotransmitter transporter encoded by the Drosophila inebriated gene, Proc Natl Acad Sci USA 93:13262-13267.

Yager J, Richards S, Hekmat-Scafe DS, Hurd DD, Sundaresan V, Caprette DR,
Saxton WM, Carlson JR, Stern M (2001) Control of Drosophila perineurial glial growth by interacting neurotransmitter-mediated signaling pathways. Proc Natl Acad Sci USA 98:10445-10450.

Yang FC, Ingram DA, Chen S, Hingtgen DM, Ratner N, Monk KR, Clegg T, White H, Mead L, Wenning MJ, Williams DA, Kapur R, Atkinson SJ, Clapp DW (2003) Neurofibromin-deficient Schwann cells secrete a potent migratory stimulus for Nf1 +/- mast cells. J Clin Invest 112:1851-1861.

Yuan LL, Ganetzky B (1999) A glial-neuronal signaling pathway revealed by mutations in a neurexin-related protein. Science 283:1343-1345.

Zhu Y, Ghosh P, Charnay P, Burns DK, Parada LF (2002) Neurofibromas in NF1: Schwann cell origin and role of tumor environment. Science 296:920-922. 